\title{
Linking snow depth to avalanche release area size: measurements from the Vallée de la Sionne field site
}

\author{
Jochen Veitinger and Betty Sovilla \\ WSL Institute for Snow and Avalanche Research SLF, Unit Snow Avalanches and Prevention, Davos, Switzerland \\ Correspondence to: Jochen Veitinger (veitinger@slf.ch)
}

Received: 5 January 2016 - Published in Nat. Hazards Earth Syst. Sci. Discuss.: 29 January 2016

Revised: 6 July 2016 - Accepted: 12 July 2016 - Published: 17 August 2016

\begin{abstract}
One of the major challenges in avalanche hazard assessment is the correct estimation of avalanche release area size, which is of crucial importance to evaluate the potential danger that avalanches pose to roads, railways or infrastructure. Terrain analysis plays an important role in assessing the potential size of avalanche releases areas and is commonly based on digital terrain models (DTMs) of a snowfree summer terrain. However, a snow-covered winter terrain can significantly differ from its underlying, snow-free terrain. This may lead to different, and/or potentially larger release areas. To investigate this hypothesis, the relation between avalanche release area size, snow depth and surface roughness was investigated using avalanche observations of artificially triggered slab avalanches over a period of 15 years in a high-alpine field site. High-resolution, continuous snow depth measurements at times of avalanche release showed a decrease of mean surface roughness with increasing release area size, both for the bed surface and the snow surface before avalanche release. Further, surface roughness patterns in snow-covered winter terrain appeared to be well suited to demarcate release areas, suggesting an increase of potential release area size with greater snow depth. In this context, snow depth around terrain features that serve as potential delineation borders, such as ridges or trenches, appeared to be particularly relevant for release area size. Furthermore, snow depth measured at a nearby weather station was, to a considerable extent, related to potential release area size, as it was often representative of snow depth around those critical features where snow can accumulate over a long period before becoming susceptible to avalanche release. Snow depth - due to its link to surface roughness - could therefore serve as a highly useful variable with regard to potential release area definition for varying snow cover scenarios, as, for example,
\end{abstract}

the avalanche hazard assessment for transport routes or ski resorts.

\section{Introduction}

Avalanche release is the result of a series of mechanical actions involving terrain, snow cover and meteorological conditions, and the understanding of avalanche release at the level of the single mechanical processes is very complex (Schweizer et al., 2003). Terrain is the only constant, and therefore often serves as a basis for release area delimitation in avalanche hazard management and mitigation (Veitinger et al., 2015; Bühler et al., 2013; Maggioni and Gruber, 2003). While basing release area estimation on terrain analysis may be valid for extreme avalanches where only coarse-scale terrain features such as major ridges are relevant to delimit potential release areas, it reaches its limit when smaller, more frequent avalanches have to be assessed, as for example the optimisation temporal mitigation measures for road and ski resort protection.

The potential release area size of such avalanches is often influenced by smaller terrain features, which may hinder a fracture to propagate and delimit the release area. However, during and after snowfall events, wind (Gauer, 2001), snow gliding (Peitzsch et al., 2015) and avalanches (Sovilla et al., 2010; Gruber, 2007) redistribute snow and smooth the finescale morphology of the terrain accordingly by filling irregularities. These processes can have a significant impact on size and location of avalanche release areas.

To understand the formation of avalanches, one has to recognise that the winter snowpack consists of layers of different density or cohesion as a result of intermittent snow- 
fall periods and changing meteorological conditions. Slab avalanches form due to the failure of a cohesive layer (slab) overlaying a less cohesive layer (a so-called weak layer). Accordingly, the bed surface, defined as the sliding plane of the slab (just below the weak layer), may either be the ground or, most often, an underlying snow layer. In a shallow snowpack, terrain roughness present at bed surface can have a stabilising function, hindering the formation of continuous weak layers (Schweizer et al., 2003) as well as providing mechanical support to the slab (McClung, 2001; van Herwijnen and Heierli, 2009). As a result, predominately small and localised release areas form. With increasing snow accumulation, surface roughness is progressively smoothed out (Veitinger et al., 2014), and terrain features buried in the snow cover below the bed surface reduce the mechanical support of a slab (McClung and Schaerer, 2002). At the same time, variability in the surface layers is reduced (Mott et al., 2010) and the formation of continuous weak layers and slabs is facilitated (Simenhois and Birkeland, 2008). Under these conditions, wider release areas may form.

These observations raise the question of whether snow depth is related to avalanche release area size. As surface roughness generally decreases with increasing snow accumulation, snow depth could serve as a useful parameter to define avalanche release area scenarios as a function of snow distribution. This could be an important step forward towards a more snow-cover-dependent avalanche hazard assessment, as for example, for transport routes or ski resorts.

Therefore, in this study, the relation between release area size and surface roughness of artificial triggered avalanches at the Vallée de la Sionne field site is evaluated. Further, snow depth at a nearby weather station and - when available snow depth measured by laser scanning and photogrammetry in the release area before and after avalanche release is compared to potential release area size. We investigate in particular how the local snow distribution affects location and extent of observed avalanche release areas.

\section{Methods}

\subsection{Surface roughness}

The main aim of this study is to evaluate whether changing surface roughness with increasing snow accumulation is related to avalanche release area size. For this purpose, the vector ruggedness measure developed by Sappington et al. (2007), which has been shown to capture the influence of snow depth on surface roughness (Veitinger et al., 2014), is used to compute the irregularity of the terrain. It is a socalled vector dispersion method (Grohmann et al., 2011), which compares the orientation of normal vectors of a given patch of surface with the orientations of neighbouring surface patches. The degree of variability in the orientations serves as a measure of the irregularity of the topographical surface.
Figure 1 illustrates the principle of vector dispersion methods.

In more detail, the vector ruggedness measure is based on changes of slope and aspect in a given neighbourhood around a centre pixel of a digital terrain model (DTM). Biquadratic polynomials are used as a basis for the computation of slope and aspect:

$z=a x^{2}+b y^{2}+c x y+d x+e y+f$,

where $z$ corresponds to the elevation estimate at a point $(x, y)$ and $a-f$ are the coefficients that define the quadratic surface (Evans, 1980).

Direction (aspect) and magnitude (slope) of the steepest gradient at the central grid cell of the fitted surface are determined by calculating the rate of change in $x$ and $y$ direction:

$$
\frac{\mathrm{d} z}{\mathrm{~d} x y}=\left(\sqrt{\left(\frac{\mathrm{d} z}{\mathrm{~d} x}\right)^{2}+\left(\frac{\mathrm{d} z}{\mathrm{~d} y}\right)^{2}}\right) .
$$

The partial derivatives for $x$ and $y$ are noted as

$\frac{\mathrm{d} z}{\mathrm{~d} x}=2 a x+c y+d$

and

$\frac{\mathrm{d} z}{\mathrm{~d} y}=2 b y+c x+e$.

In order to obtain the parameter at the central point of the surface $(x=y=0)$, Eqs. (3) and (4) are integrated into Eq. (2), and note

$$
\frac{\mathrm{d} z}{\mathrm{~d} x y}=\sqrt{d^{2}+e^{2}} \text {. }
$$

Slope $(\alpha)$ is thus given as

$$
\alpha=\arctan \sqrt{d^{2}+e^{2}} \text {. }
$$

Likewise, aspect is defined as

$$
\beta=\arctan \frac{e}{d} \text {. }
$$

Based on these definitions, roughness is computed as follows.

Normal unit vectors of every grid cell of a digital elevation model (DEM) are decomposed into $x, y$ and $z$ components (Fig. 2):

$$
\begin{aligned}
& z=1 \cdot \cos (\alpha) \\
& d_{x y}=1 \cdot \sin (\alpha) \\
& x=d_{x y} \cdot \cos (\beta) \\
& y=d_{x y} \cdot \sin (\beta) .
\end{aligned}
$$

A resultant vector $|\boldsymbol{r}|$ is then obtained for every pixel by summing up the single components of the centre pixel and its eight neighbours using a moving window technique.

$$
|\boldsymbol{r}|=\sqrt{\left(\sum x\right)^{2}+\left(\sum y\right)^{2}+\left(\sum z\right)^{2}}
$$




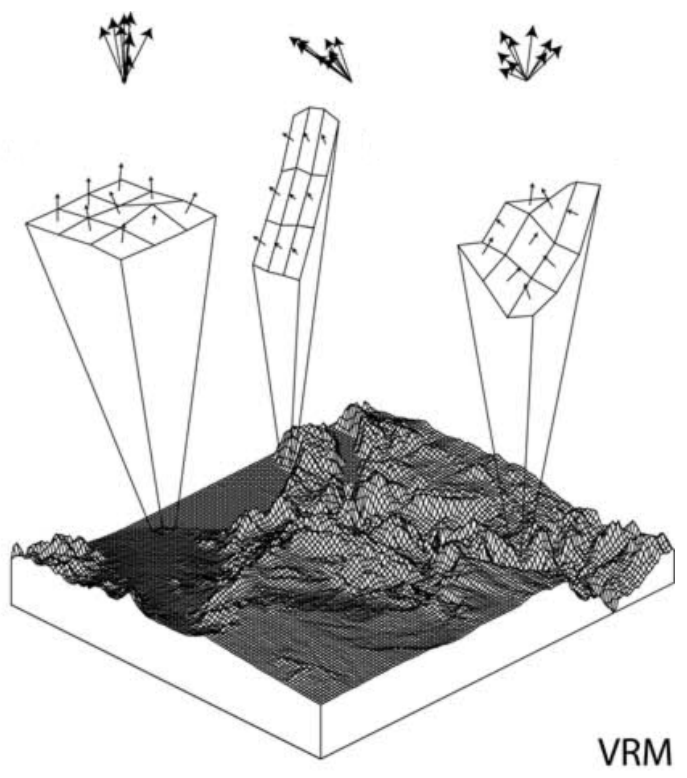

Figure 1. The graphic shows the measurement principle of vector dispersion methods. The dispersion of vectors perpendicular to the terrain surface defines the degree of surface roughness. Graphic from Sappington et al. (2007).

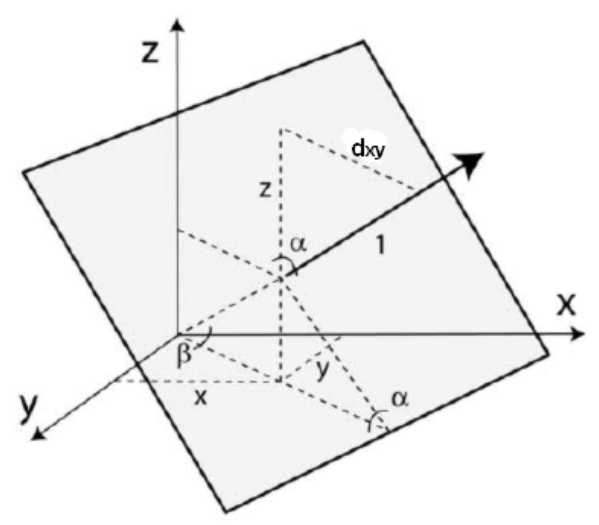

Figure 2. Decomposition of normal unit vectors of a DTM grid cell into $x, y$ and $z$ components using slope $\alpha$ and aspect $\beta$. Graphic from Sappington et al. (2007).

as shown in Fig. 3b. The magnitude of the resultant vector is then normalised by the number of grid cells and subtracted from 1 :

$\boldsymbol{R}=1-\frac{|\boldsymbol{r}|}{9}$

where $\boldsymbol{R}$ is the vector ruggedness measure.

It is evident that measured surface roughness depends on the resolution of the DEM and the size of the neighbourhood window. In this study, a resolution of $0.5 \mathrm{~m}$ and a window size of $3 \times 3$ pixels are used to compute roughness. In this way, it is ensured that roughness elements down to the size of single rocks or boulders, which can affect avalanche release propensity, are captured.

\subsection{Study area and data acquisition methods}

The site of Vallée de la Sionne (VdlS) is located in the southwestern part of Switzerland in the Canton of Valais, near Sion (Fig. 4). The area upon which we focus in this study corresponds to typical locations of avalanche release areas, and is characterised by elevations between 2460 and $2679 \mathrm{~m}$ a.s.l., whilst orientation ranges from $\mathrm{E}$ to SE. The VdlS field site can be divided into three different basins characterised by distinct topography: Crêta Besse 1 (CB1) is steepest and roughest with a mean slope of $42.4^{\circ}$, whereas Crêta Besse 2 (CB2) is less steep with a mean slope of $36.2^{\circ}$ and a homogeneous terrain surface without major ridges or cliffs. CB1 is separated from CB2 by a prominent rocky ridge. The Pra Roua (PR) basin has the smoothest terrain surface with an average steepness between the one of CB1 and CB2 and a mean slope of $37.7^{\circ}$.

Avalanches are artificially released by explosives from a helicopter. Generally, experiments were only performed after a significant snowfall $(>0.8 \mathrm{~m})$ where large avalanches can be expected. Snow depth data are obtained from a nearby weather station providing half-hour data about snow depth (HS) and other meteorological parameters such as wind and temperature. Artificial avalanche release is generally performed at several locations ranging from Pra Roua to CB2. Until the winter season 2004/2005, snow depth distribution before and after avalanche release was recorded by photogrammetry (Vallet et al., 2001). Measurements were mostly restricted to the area around the crown fracture, with an average point spacing of $5 \mathrm{~m}$. The accuracy (rms; root mean square) of the measurements is around $0.25 \mathrm{~m}$ when compared to manual measurements of fracture depth. Since the year $2005 / 2006$, photogrammetry was replaced by a helicopter-based, airborne laser scanning (ALS) system, providing continuous, high-resolution $(0.5 \mathrm{~m})$ snow depth data. The vertical accuracy of the data is $0.10 \mathrm{~m}$. A detailed description of the method and the precision of the measurements can be found in Sovilla et al. (2010).

\subsection{Selection and analysis of existing release area data}

In this paper, we focus our study on avalanches that were triggered at two different locations. One is the rather smooth area of $\mathrm{CB} 2$ and the second is the south-western part of CB1, consisting of a steeper, more irregular surface than CB2. Figure 5 shows the release areas of all selected avalanches between the years 1998 and 2015 and the approximate locations of the trigger points. Frequently, spontaneous releases occurred in the PR basin prior to artificial avalanche release in CB1, which prevented most release areas to extend into the PR basin. Therefore, for release area no. 103, only the part that is located in the CB1 basin is considered. All avalanches 


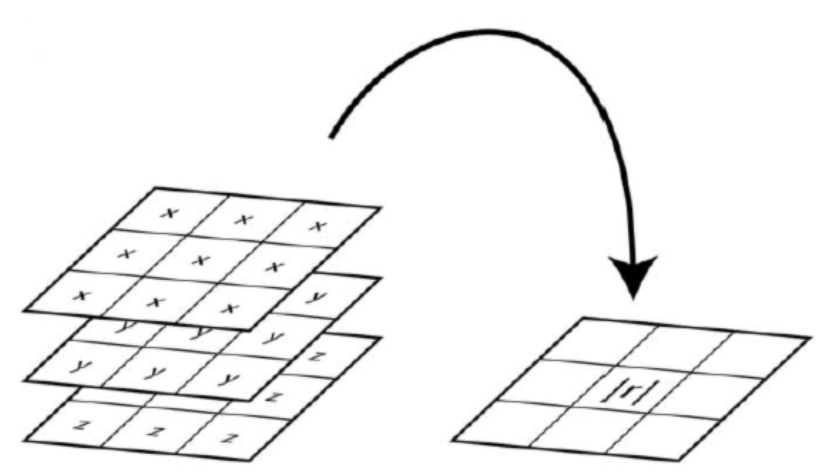

Figure 3. Resultant vector, $\boldsymbol{r}$, is obtained by summing up the $x, y$ and $z$ components of all pixels, $n$, within the neighbourhood window. Graphics from Sappington et al. (2007).

are dry slab avalanches. Very small avalanches that did not show any fracture propagation after the initial explosion were not considered in the analysis.

In a next step, we collected and calculated snow cover parameters from the available photogrammetry and laser scanning measurements. In the case of photogrammetry, values were obtained from Vallet et al. (2001) and technical reports issued by SLF (Gruber et al., 2002; Sovilla et al., 2004a, b), indicating mean snow depth before $\left(\overline{\mathrm{HS}_{1}}\right)$ and after avalanche release $\left(\overline{\mathrm{HS}_{2}}\right)$, as well as the vertical distance between the two (fracture depth $\bar{d}$ ) along the fracture line or within the entire release area when available. It has to be noted that snow distribution at the crown is often not representative of the entire release area and restricts the comparison between the two measurements.

In the case of the laser scanning measurements (Sovilla et al., 2010, 2016), snow depth parameters were derived from difference maps subtracting raster maps of the winter terrain before and after avalanche release from the summer terrain (or by subtracting the two snow surfaces in the case of fracture depth). Mean snow depth before $\left(\overline{\mathrm{HS}_{1}}\right)$ and after avalanche release $\left(\overline{\mathrm{HS}_{2}}\right)$, as well as mean fracture depth $(\bar{d})$, was calculated by computing the mean over all raster cells within the release area from the corresponding difference maps. Snow depth, HS, and new snow depth, HN, were derived from the weather station, where new snow depth is defined as the difference in snow depth between avalanche release and the start of the preceding snowfall period. Release area width, $\mathrm{W}$, is defined as the maximum horizontal distance between the two flanks of the release area.

Further, to take full advantage of the high-resolution snow depth measurements since the season 2005/2006, we prepared another dataset that covers all avalanches retrieved with ALS measurements independent of their location (Sovilla et al., 2010, 2016). This also includes avalanches that are released in the PR basin as well as avalanches that are released all over CB1. The dataset consists of two sets

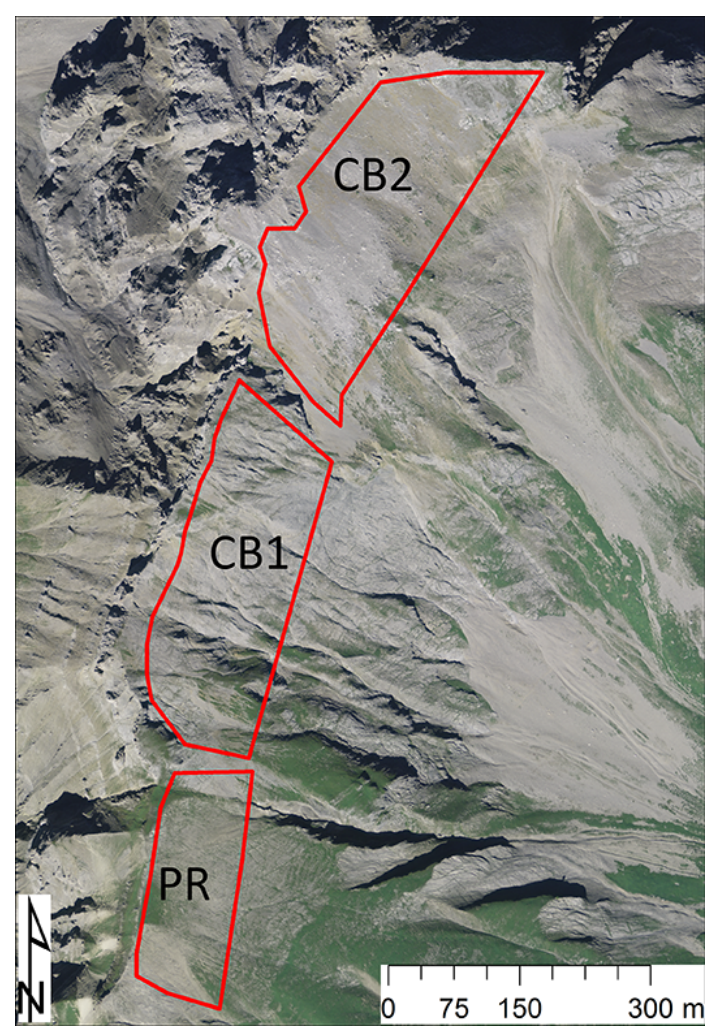

Figure 4. Field site Vallée de la Sionne near Sion. In red, the locations of the analysed basins, PR, CB1 and CB2, are marked. Pixmaps $^{\circledR} 2016$ swisstopo (5 704000000 ).

of 6 dry slab avalanches that were artificially triggered on 8 March 2006, and on 3 February 2015 (Fig. 6).

For these avalanches, a more in-depth analysis was performed. Beside mean fracture depth $(\bar{d})$, mean snow depth before $\left(\overline{\mathrm{HS}_{1}}\right)$ and after avalanche release at the bed surface $\left(\overline{\mathrm{HS}_{2}}\right)$, as well as mean roughness of the snow-free terrain $\left(\overline{R_{T}}\right)$, the snow surface before avalanche release $\left(\overline{R_{1}}\right)$ and the bed surface after avalanche release $\left(\overline{R_{2}}\right)$, was calculated for all triggered avalanches (Table 3 ). Surface roughness was derived on a pixel basis using the methodology as described in Sect. 2.1, followed by the computation of the mean over all surface roughness pixels within the extent of the release area.

\subsection{Relating release area size to surface roughness and snow depth}

The relation between surface roughness and release area size is explored using all avalanches where surface roughness computations are available (Fig. 6). Release area size is plotted on the one hand against mean surface roughness of the snow surfaces before and after avalanche release as well as against terrain roughness. On the other hand, surface roughness maps of different snow covers are produced. We investigate qualitatively whether varying surface roughness with different snow covers is related to avalanche release area size. 
Table 1. Number, date, release area width $(W)$, snow depth (HS) and new snow depth $(\mathrm{HN})$ measured at the weather station of Donin du Jour; mean snow depth before $\left(\overline{\mathrm{HS}_{1}}\right)$ and after avalanche release $\left(\overline{\mathrm{HS}_{2}}\right)$ and mean fracture depth $(\bar{d})$ for avalanche release areas occurring before the winter season $2005 / 2006$. Further, the spatial measurement extent is provided.

\begin{tabular}{lccrrrrrr}
\hline Aval no. & Date & $\mathrm{W}(\mathrm{m})$ & $\mathrm{HS}\left(\mathrm{m}^{-2}\right)$ & $\mathrm{HN}\left(\mathrm{m}^{-2}\right)$ & $\overline{\mathrm{HS}_{1}}\left(\mathrm{~m}^{-2}\right)$ & $\overline{\mathrm{HS}_{2}}\left(\mathrm{~m}^{-2}\right)$ & $\bar{d}\left(\mathrm{~m}^{-2}\right)$ & Extent \\
\hline CB1 & & & & & & & & \\
\hline no. 103 & 10 Feb 1999 & 165 & 350 & 140 & 200 & 98 & 102 & Crown \\
no. 509 & 07 Feb 2003 & 285 & 360 & 90 & 291 & 146 & 145 & Area \\
no. 628 & 19 Jan 2004 & 120 & 300 & 110 & 314 & 195 & 119 & Area \\
\hline CB2 & & & & & & & & \\
\hline no. 301 & 30 Jan 1999 & 220 & 260 & 120 & 304 & 141 & 163 & Crown \\
no. 200 & 24 Feb 1999 & 760 & 440 & 100 & 295 & 100 & 195 & Crown \\
no. 506 & 31 Jan 2003 & 470 & 290 & 60 & $\times$ & $\times$ & 60 & Crown \\
no. 629 & 19 Jan 2004 & 500 & 300 & 110 & 330 & 153 & 176 & Area \\
\hline
\end{tabular}

Table 2. Number, date, release area width $(W)$, snow depth (HS) and new snow depth (HN) measured at the weather station of Donin du Jour; mean snow depth before $\left(\overline{\mathrm{HS}_{1}}\right)$ and after avalanche release $\left(\overline{\mathrm{HS}_{2}}\right)$ and mean fracture depth $(\bar{d})$ for avalanche release areas occurring from the winter season 2005/2006 onwards.

\begin{tabular}{|c|c|c|c|c|c|c|c|}
\hline Aval no. & Date & $\mathrm{W}(\mathrm{m})$ & $\mathrm{HS}\left(\mathrm{m}^{-2}\right)$ & $\mathrm{HN}\left(\mathrm{m}^{-2}\right)$ & $\overline{\mathrm{HS}_{1}}\left(\mathrm{~m}^{-2}\right)$ & $\overline{\mathrm{HS}_{2}}\left(\mathrm{~m}^{-2}\right)$ & $\bar{d}\left(\mathrm{~m}^{-2}\right)$ \\
\hline \multicolumn{8}{|l|}{ CB1 } \\
\hline no. 816 & 8 Mar 2006 & 105 & 290 & 120 & 334 & 190 & 144 \\
\hline no. 917 & 26 Mar 2008 & 110 & 350 & 80 & - & - & - \\
\hline no. 20150016 & 3 Feb 2015 & 90 & 210 & 110 & 221 & 104 & 118 \\
\hline \multicolumn{8}{|l|}{$\mathrm{CB} 2$} \\
\hline no. 726 & 17 Feb 2005 & 280 & 220 & 70 & - & - & 170 \\
\hline no. 817 & 8 Mar 2006 & 480 & 290 & 120 & 366 & 229 & 137 \\
\hline no. 918 & 26 Mar 2008 & 310 & 350 & 80 & - & - & - \\
\hline no. 20150020 & 3 Feb 2015 & 170 & 210 & 110 & 236 & 56 & 180 \\
\hline
\end{tabular}

Table 3. Number, date, release area size $\left(A\right.$, mean snow depth before $\left(\overline{\mathrm{HS}_{1}}\right)$ and after avalanche release $\left(\overline{\mathrm{HS}_{2}}\right)$, mean fracture depth $(\bar{d})$, mean roughness of the snow-free terrain $\left(\overline{R_{T}}\right)$, the snow surface before avalanche release $\left(\overline{R_{1}}\right)$ and the bed surface after avalanche release $\left(\overline{R_{2}}\right)$ for all avalanche release areas with ALS measurements in VdlS.

\begin{tabular}{|c|c|c|c|c|c|c|c|c|}
\hline Aval no. & Date & Size A $\left(\mathrm{m}^{2}\right)$ & $\overline{\mathrm{HS}_{1}}\left(\mathrm{~m}^{-2}\right)$ & $\overline{\mathrm{HS}_{2}}\left(\mathrm{~m}^{-2}\right)$ & $\bar{d}\left(\mathrm{~m}^{-2}\right)$ & $\overline{R_{T}}$ & $\overline{R_{1}}$ & $\overline{R_{2}}$ \\
\hline no. $816 a$ & 8 Mar 2006 & 21874 & 319 & 154 & 165 & 0.0014 & 0.0004 & 0.0009 \\
\hline no. $816 b$ & 8 Mar 2006 & 6944 & 334 & 190 & 144 & 0.0024 & 0.0005 & 0.0015 \\
\hline no. 2006003 & 8 Mar 2006 & 1906 & 296 & 142 & 162 & 0.0019 & 0.0013 & 0.0027 \\
\hline no. 2006004 & 8 Mar 2006 & 1265 & 343 & 148 & 195 & 0.0018 & 0.0006 & 0.0016 \\
\hline no. 2006005 & 8 Mar 2006 & 2885 & 261 & 112 & 149 & 0.0024 & 0.0009 & 0.0023 \\
\hline no. 817 & 8 Mar 2006 & 78390 & 366 & 229 & 137 & 0.0019 & 0.0003 & 0.0007 \\
\hline no. 20150016 & 3 Feb 2015 & 10816 & 190 & 74 & 116 & 0.0012 & 0.0003 & 0.0005 \\
\hline no. 20150017 & 3 Feb 2015 & 3508 & 221 & 104 & 118 & 0.0035 & 0.0009 & 0.0015 \\
\hline no. 20150019 & 3 Feb 2015 & 622 & 234 & 47 & 187 & 0.0016 & 0.0003 & 0.0018 \\
\hline no. 20150021 & 3 Feb 2015 & 341 & 156 & 31 & 125 & 0.0036 & 0.0010 & 0.0035 \\
\hline no. 20150022 & 3 Feb 2015 & 974 & 185 & 49 & 136 & 0.0032 & 0.0025 & 0.0035 \\
\hline no. 20150020 & 3 Feb 2015 & 10909 & 236 & 56 & 180 & 0.0016 & 0.0002 & 0.0010 \\
\hline
\end{tabular}




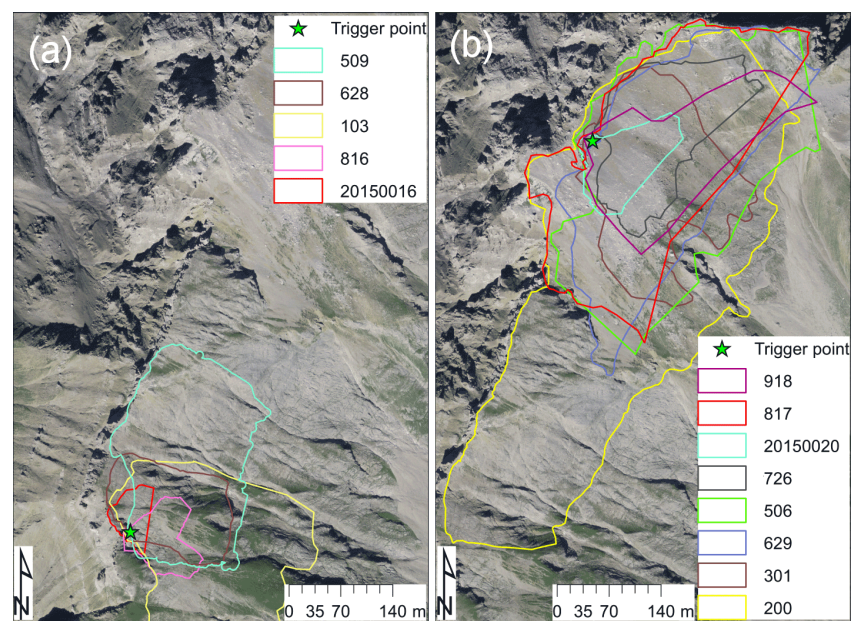

Figure 5. Extent of all selected release areas in (a) the southwestern part of CB1 and (b) CB2.

Further, release area size is directly compared to several snow cover parameters. In a first step, release area size of avalanches occurring at the same locations is plotted against mean snow depth at bed surface measured by ALS. As laser scanner measurements are not available for most of the avalanches, release area width was then compared to snow depth measured at the weather station. To this end, a linear regression between release area width, W, and snow depth, HS, was performed. To account for the non-linear increase of release area size with snow depth, logarithmic transformations of release area width were used in the regression. In this way, the impact of large, non-linear differences on the correlation is reduced. As avalanche release areas are often confined by terrain features such as ridges and gullies, we explore the local snow distribution around terrain breaks in a last step. To this end, representative snow depth profiles, across locations where release areas are typically arrested, have been created. The exact locations of the snow depth profiles are shown in Fig. 13.

\section{Results and interpretation}

\subsection{Assessment of release area size}

Table 1 shows an overview of all released avalanches measured with photogrammetry. Snow depth measurements before and after avalanche release were either performed in the entire release area or along the avalanche crown. An overview of all released avalanches measured with ALS can be observed in Table 2. Using ALS, continuous snow depth measurements were performed over the entire release area.

It can be observed that avalanche release areas in the CB2 basin are typically large, with release area widths ranging from 170 to $500 \mathrm{~m}$, covering large areas of the basin surface. Normally, the release area does not extend into the CB1 basin
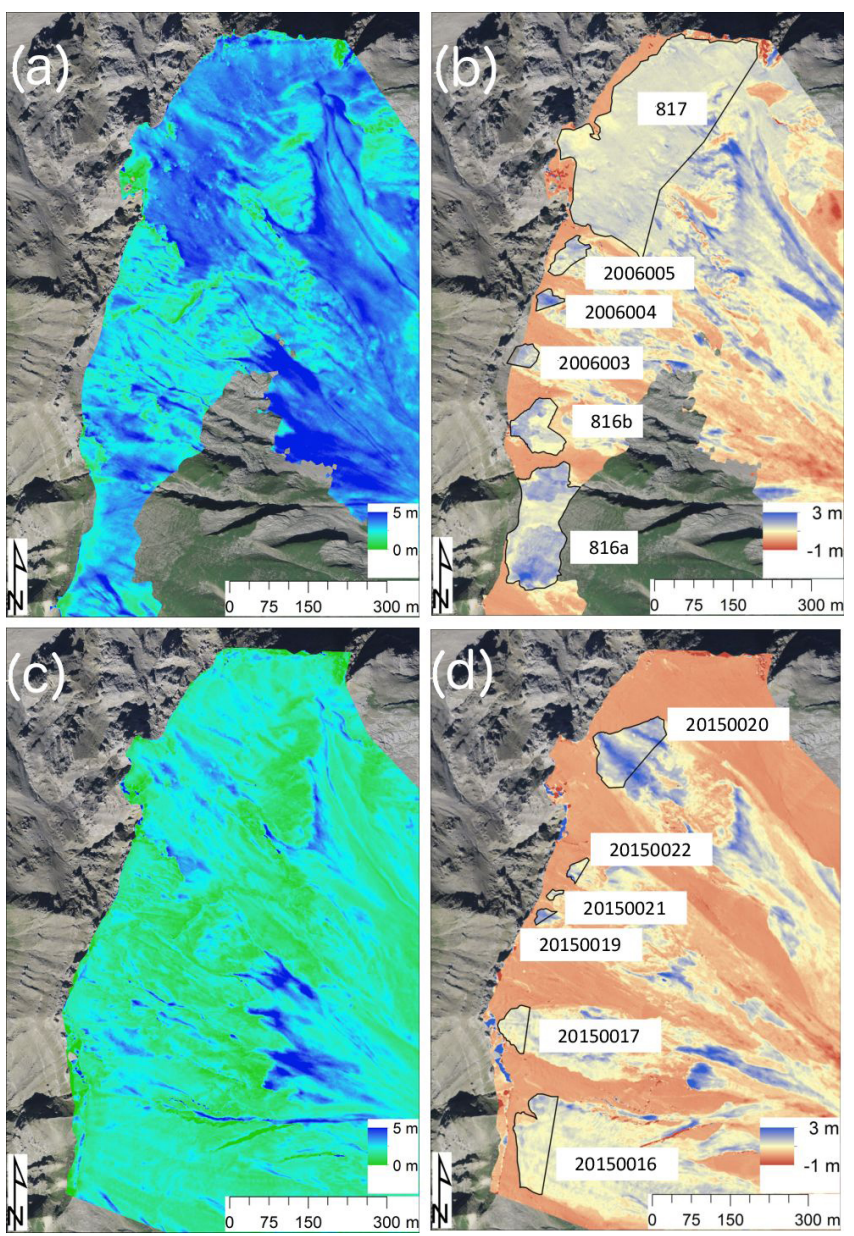

Figure 6. Snow depth before avalanche release on (a) 8 March 2006 and (c) 3 February 2015. Difference of snow depth before and after artificial avalanche release obtained from the scans of (b) 8 March 2006 and (d) 3 February 2015. The release zones and their avalanche tracks are clearly visible. Further, release area numbers according to Table 3 are also shown.

and is confined by the clear topographical break between CB1 and CB2. In one case, during the catastrophic winter of 1998/1999 (Gruber and Margreth, 2001), an avalanche was released simultaneously over the entire $\mathrm{CB} 2$ and $\mathrm{CB} 1$ basin over a width of $760 \mathrm{~m}$. In contrast, release areas in the CB1 basin are smaller, with release area widths between 90 and $285 \mathrm{~m}$. Release areas mostly occur in sub-areas of the basin, which is subdivided by many gullies and ridges.

Table 3 describes release area properties of all avalanches that were captured with ALS measurements, comprising all possible locations ranging from the PR to the $\mathrm{CB} 2$ basin. Four large slabs $\left(>10000 \mathrm{~m}^{2}\right)$ were observed where the fracture propagated over a larger distance within the very smooth basins of CB2 and PR (no. 816a and no. 817, no. 20150016 and no. 20150020). Four medium-sized slabs $\left(1500 \mathrm{~m}^{2}-10000 \mathrm{~m}^{2}\right)$ were observed on the southern end of CB1 (no. 816b and no. 20150017) and on CB1 (no. 2006004, 


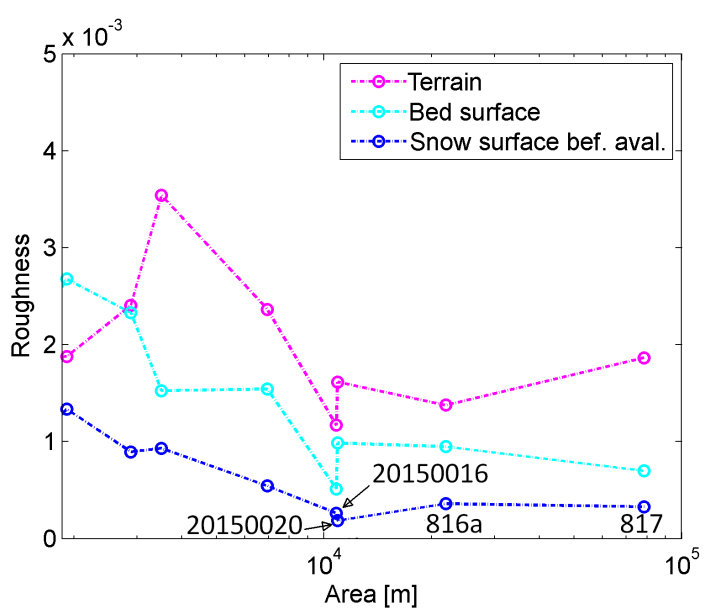

Figure 7. Release area size as a function of its surface roughness at the level of the snow-free terrain (red), the bed surface (light blue) and the snow surface prior to avalanche release (dark blue).

no. 2006005). The other slabs within CB1 were rather small $\left(<1500 \mathrm{~m}^{2}\right)$ with only very little fracture propagation (no. 2006003, no. 20150019, no. 20150021, no. 20150022). Avalanche no. 816a and no. 816b also triggered deeper layers of the snowpack. Interestingly, avalanche no. $816 \mathrm{~b}$ released due to the detonation, whereas avalanche no. 816a was triggered remotely by avalanche no. $816 \mathrm{~b}$.

\subsection{Release area size and roughness}

Figure 7 shows release area size as a function of mean roughness of summer terrain, $\overline{R_{T}}$, bed surface, $\overline{R_{2}}$ and snow surface prior to avalanche release $\overline{R_{1}}$ based on avalanches shown in Table 3. However, we restricted our analysis to mediumand large-sized release areas $\left(>1500 \mathrm{~m}^{2}\right)$, as no fracture propagation was observed for smaller release areas after the initial explosion.

It can be observed that the avalanche bed surface is generally less rough when compared with the underlying terrain. At the same time, the snow surface prior to avalanche release is always smoother than the underlying bed surface (and the terrain). This illustrates the progressive terrain smoothing within avalanche release areas. The results further show a clear tendency of decreasing surface roughness with increasing release area size. This tendency is more pronounced for the bed surface and the snow surface before avalanche release; to a lesser extent for terrain roughness. This suggests that the winter terrain appears to be more explanatory of potential release area size than the summer terrain.

However, the decrease of average snow surface roughness is limited to a certain avalanche size. Release areas exceeding the critical size of approximately $10000 \mathrm{~m}^{2}$ show similar surface roughness, as for example release areas no. 816, no. 817, no. 20150016 and no. 20150020. As an example, Fig. 8 shows images of release areas no. 817 and no. 20150020.
Surface roughness inside the release area was similar for both avalanches (Fig. 7). However, for release area no. 817, the fracture could fully propagate through the entire basin and the fracture stopped at the basin boundary (Fig. 8a), where larger boulders and a ridge delimit the basin entity. In contrast, for release area no. 20150020 (Fig. 8b), terrain features at the crown and the lateral boundaries of the slab are observed in the centre of the basin, potentially hindering the fracture to fully propagate. This suggests that once a critical minimum value of average surface roughness is reached, a fracture self-propagates until it is arrested by major terrain features or major changes in snow cover.

This is supported by Fig. 9, which shows surface roughness for the summer terrain and the three winter terrain surfaces of 8 December 2010, 3 February 2015 and 8 March 2006. The winter surfaces are characterised by mean snow depths, calculated over the entire VdlS basin area, ranging from $1.2 \mathrm{~m}$ in 2010 over $2.4 \mathrm{~m}$ in 2015 to $3.7 \mathrm{~m}$ in 2006 . It can be observed that increasingly large and connected areas of low surface roughness are formed with increasing snow depth. Moreover, the roughness patterns caused by different snow covers appear to be well suited to demarcate the observed release areas. Release area no. 20150020 can be associated with the roughness pattern in between the summer terrain and the one with little snow depth in the year 2010, whereas release area no. 817 corresponds rather to the snow cover of 2006 and 2015. This suggests that surface roughness corresponding to a snow cover similar to the one at avalanche release may be suited to delimit the potential size of avalanche release areas.

Interestingly, there is only little difference in surface roughness in CB2 for 2006 and 2015, despite a significant deeper snowpack in 2006. The difference in snow depth only has effects on the border of the basin, such as the ridge linking CB1 to CB2 and several features within the CB1 basin (red circles in Fig. 9). These features are more attenuated in 2006 with additional snow depth. It can be assumed that in a further increasing snowpack, they would also be cancelled out, enlarging the continuous areas of low surface roughness. This highlights the important role of snow depth for potential release area size, which will be explored in the following section.

\subsection{Release area size and snow distribution}

\subsubsection{Release area size and snow cover parameters}

Figure 10 shows mean snow depth at bed surface as a function of avalanche release area for the two sets of avalanches in 2006 and 2015 (Table 3). It is observed that avalanche release areas triggered in the deeper snowpack of 2006 are always larger compared to their similarly located avalanches of 2015. Both snow depth at bed surface and before avalanche release is consistently deeper for every single avalanche released in 2006 when compared to its counterpart in 2015. 

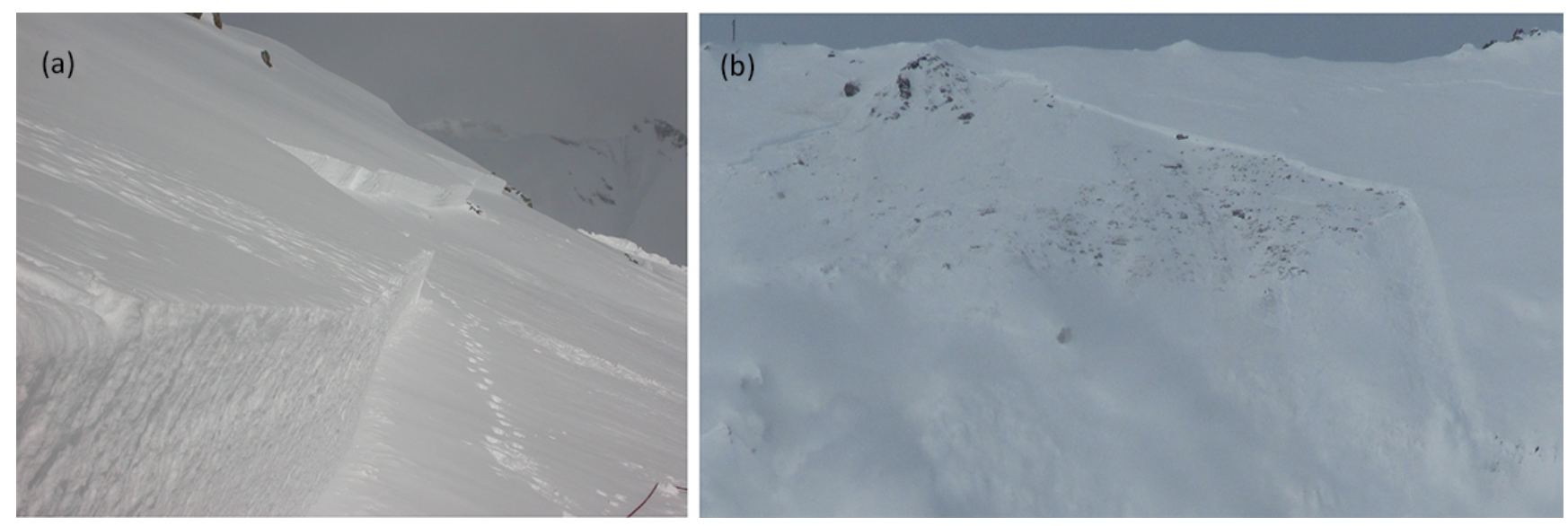

Figure 8. Images of the artificially triggered avalanches at the CB2 basin on (a) 8 March 2006 (avalanche no. 817) and (b) 3 February 2015 (avalanche no. 20150020).

These observations support our hypothesis that a deepening snow cover forms increasing areas of low surface roughness, which could have resulted in larger release areas in 2006.

This is confirmed by Fig. 11, comparing release area width of all avalanches with snow depth measured at the weather station. A significant correlation between snow depth and release area width is observed $\left(R^{2}=0.78, p=0.023\right)$ in CB2 - to a lesser extent also in CB1 $\left(R^{2}=0.70, p=0.120\right)$, which again supports the hypothesis that larger avalanche releases can form in a thicker snow cover. Moreover, smaller avalanches are observed in $\mathrm{CB} 1$ compared to $\mathrm{CB} 2$, supporting the hypothesis that rough terrain, such as $\mathrm{CB} 1$, requires more snow to form sufficiently smooth winter terrain conditions to produce large release areas. However, smaller avalanches in CB1 could also be explained by the steeper terrain of $\mathrm{CB} 1$ compared to $\mathrm{CB} 2$, generally leading to increased avalanche and sloughing activity, preventing the formation of a thick continuous snow cover.

At the same time, no correlation is observed between new snow depth and release area width (Fig. 12a) as well as between mean slab depth and release area width (Fig. 12b), suggesting that these variables alone cannot explain the differences in release area size.

\subsubsection{Release area size and local snow distribution}

The results in the previous section showed a clear relation between snow depth at the weather station and observed release area size. Further, Sect. 3.2 suggests that snow depth at critical terrain features is particularly relevant for potential release area size. This is in line with snow depth profiles at several locations in the release area (Fig. 13).

Figure 14 shows snow depth at times of avalanche release for the release areas no. 200, no. 817 and no. 20150020 along profile 1 following the crown fracture of release area no. 200 at the border between CB1 and CB2. We observe that the snowpack of release area no. 200 is, in most loca- tions, deeper compared to no. 817, which is itself consistently deeper throughout the entire profile than avalanche no. 20150020. In particular at the ridge separating CB1 from CB2, the snowpack of avalanche no. 200 appears to be significantly deeper. This shows that snow depth of release area no. 200 was not affected by the previous release of avalanche no. 301, triggered about a month earlier. Avalanche no. 301 released below the crown fracture of avalanche no. 200 and did not fully propagate through CB2. As a result, the thick snow cover at the borders of the basin remained, possibly facilitating full fracture propagation through $\mathrm{CB} 1$ in the case of avalanche no. 200, whereas the fracture of no. 817 was arrested at the prominent ridge separating CB1 from CB2. The lower snowpack for no. 20150020 resulted in an even smaller release area and did not even fully propagate through CB2. These snowpack differences are clearly shown by the weather station, which can be considered representative, at least for the border between CB1 and CB2, where previous avalanches did not occur.

This is confirmed in CB1. Two representative snow depth profiles (profiles 2 and 3, Fig. 15) show a generally good agreement between snow depth measured at the weather station and snow depth in the release area. Further, profile 2, located across the prominent gully where the avalanches no. 628 and no. 103 stopped, but no. 509 propagated through, shows a significantly larger snow depth in the gully for no. 509 than for no. 628 and no. 103. At the same time, snow depth outside the gully was similar or even lower. Again, this confirms our observations in Sect. 4.1. that snow depth at specific terrain features, which serve as delimiting borders for avalanche release, may be decisive for potential release areas size. However, in contrast to the snow covers of avalanches no. 628 , no. $816 \mathrm{~b}$ and no. 20150016, snow depth in the gully for avalanches no. 103 and no. 509 deviates significantly from the weather station measurements. Snow depth was significantly larger for release area no. 509 

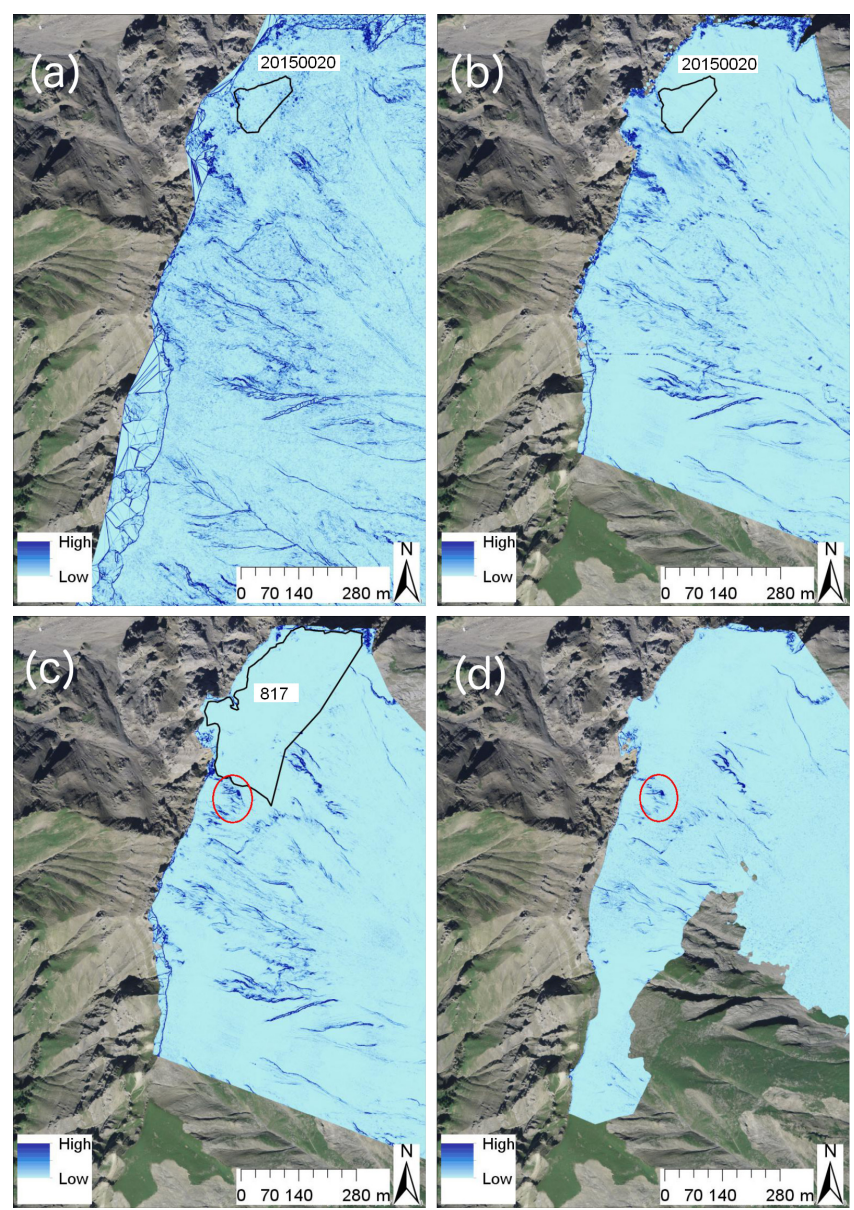

Figure 9. Surface roughness of (a) the summer terrain, (b) the winter terrain for the snow distribution of 8 December 2010, (c) the winter terrain for the snow distribution of 3 February 2015 and (d) the winter terrain for the snow distribution of 8 March 2006. In black, the outlines of avalanche release areas at CB2 are shown. The red circles show critical terrain features with different degrees of smoothing due to varying snow depth.

and significantly lower for release area no. 103 compared to the weather station measurements. Snow was probably locally removed from the gully (e.g. avalanching) in the case of no. 103, whereas it had rather accumulated for avalanche no. 509 (Fig. 15).

These observations suggest that the weather station is, in many cases, indicative of potential release area size, as it is representative of snow conditions in the release area, in particular around critical features such as ridges and rocky outcrops, which are often less affected by frequent avalanches as they require a very thick snow cover before avalanches may form. However, exceptions are possible, in particular when important snow redistribution processes occur which de- or increase fracture propagation propensity relative to snow depth measured at a nearby weather station.

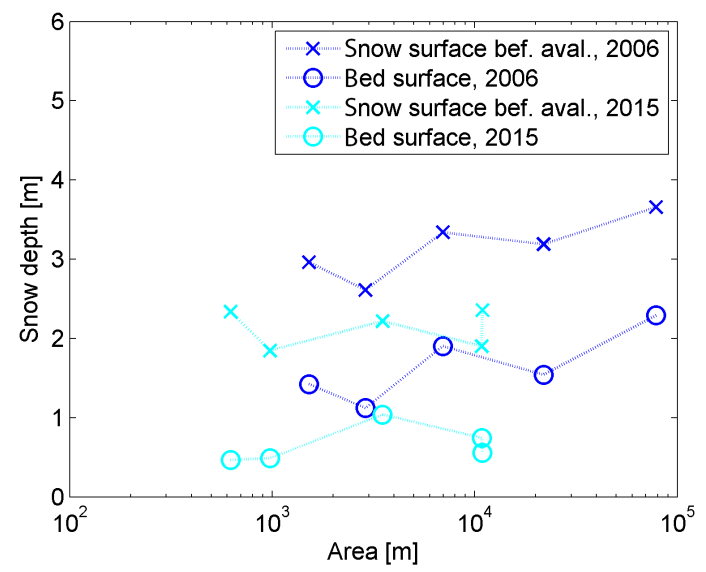

Figure 10. Release area size as a function of snow depth at the bed surfaces for the avalanches released in 2006 and in 2015 .

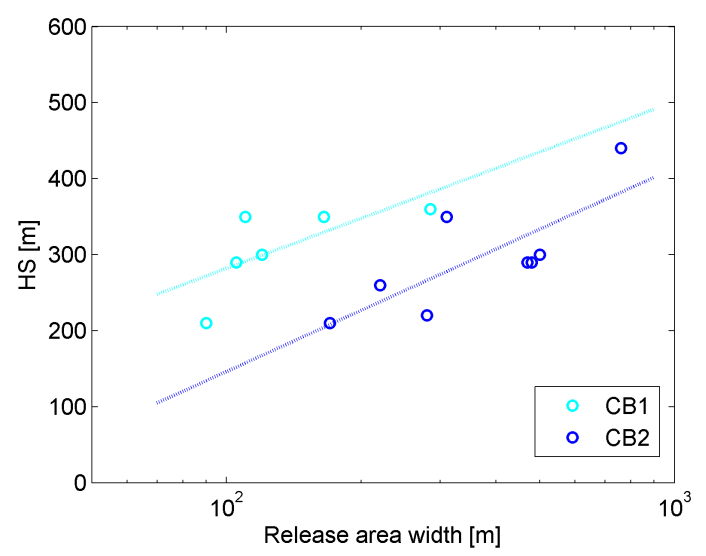

Figure 11. Release area width in the basins $\mathrm{CB} 1$ and $\mathrm{CB} 2$ as a function of snow depth measured at the weather station.

\section{Discussion}

The results revealed the connexion between increasing release area size and decreasing surface roughness at the bed surface with snow accumulation. This is in line with the current understanding of terrain smoothing processes, which reduce the mechanical support of a slab (McClung and Schaerer, 2002) and favour the formation of continuous slabs and weak layers (Schweizer et al., 2003), which can subsequently lead to potentially larger release areas. However, we also observed large release areas where snow depth at the bed surface is low and surface roughness is still present, such as no. 726 . These avalanches were characterised by large slab thickness, meaning that surface roughness at bed surface was covered by a thick layer of snow, levelling out the irregularities and forming a smooth surface at the top of the snowpack. In other words, the overlaying slab was thick enough to form a continuous layer and, ultimately, produce a wide release area. This suggests that surface roughness at the top of the snowpack may be more representative of potential release 

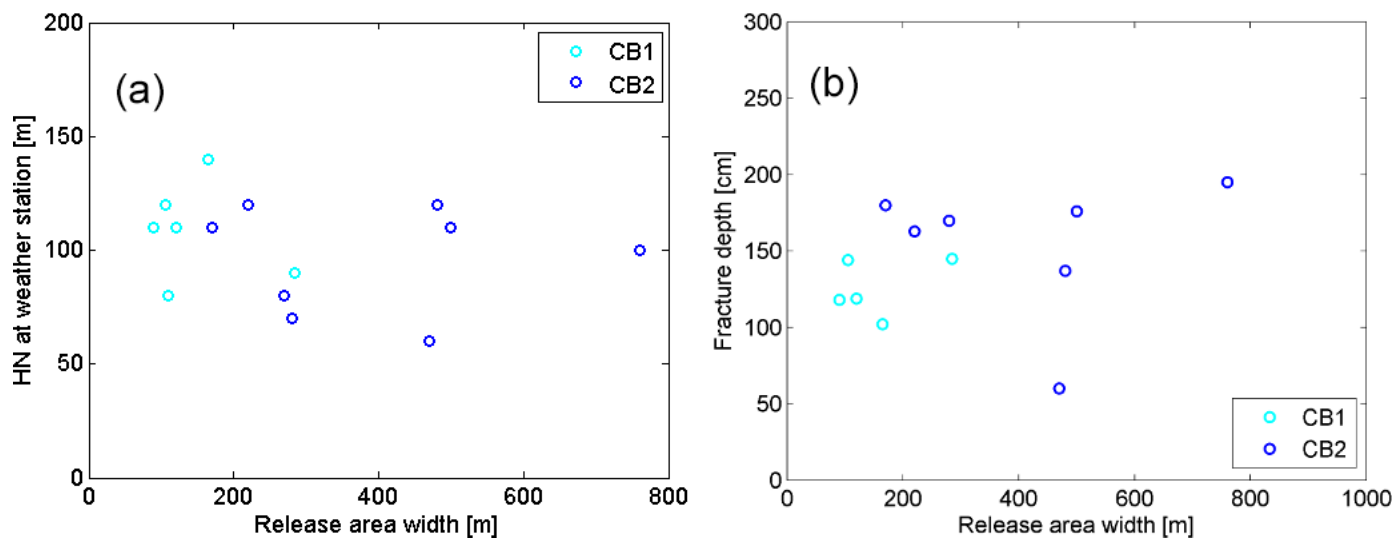

Figure 12. Release area width in the basins CB1 and CB2 as a function of (a) new snow depth of the snowfall period previous to avalanche release and (b) mean fracture depth.

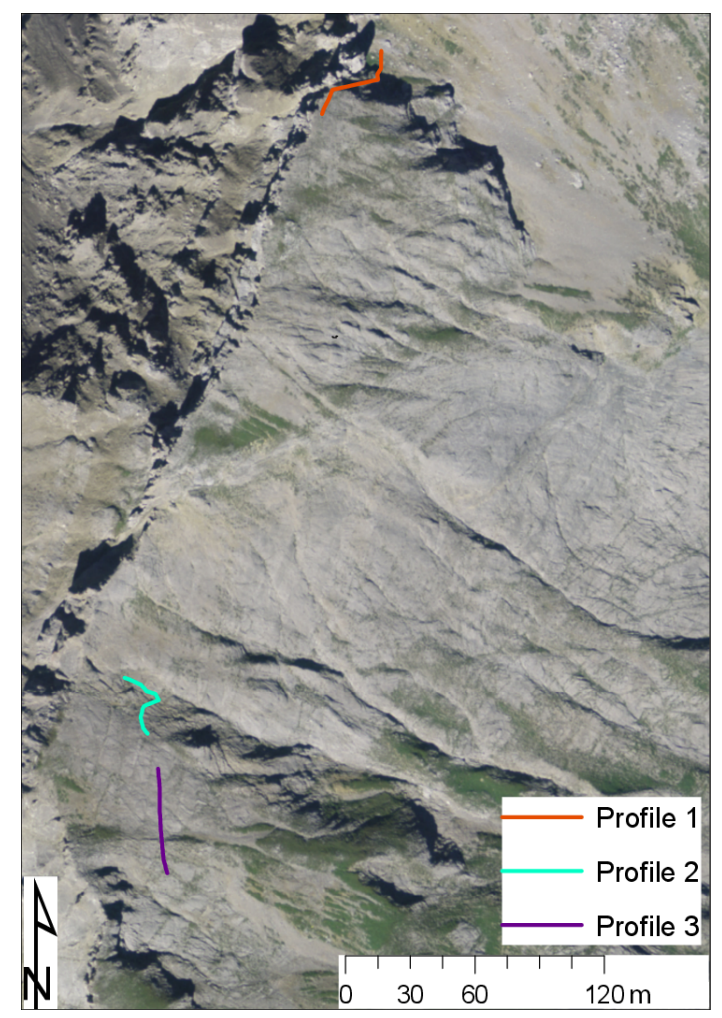

Figure 13. Locations of snow depth profiles in the CB1 basin (profiles 2 and 3) and at the border between CB1 and CB2 (profile 1).

area size than roughness of the bed surface. In this way, terrain smoothing may also be relevant for slab avalanches that are released on deeper layers in the snowpack where surface roughness is still present. This is supported by field observations, where wide release areas are not only observed for avalanches running on upper layers of the snowpack, but also for slab avalanches running on weak layers near the terrain surface (so-called deep slabs). They are known to reach im-

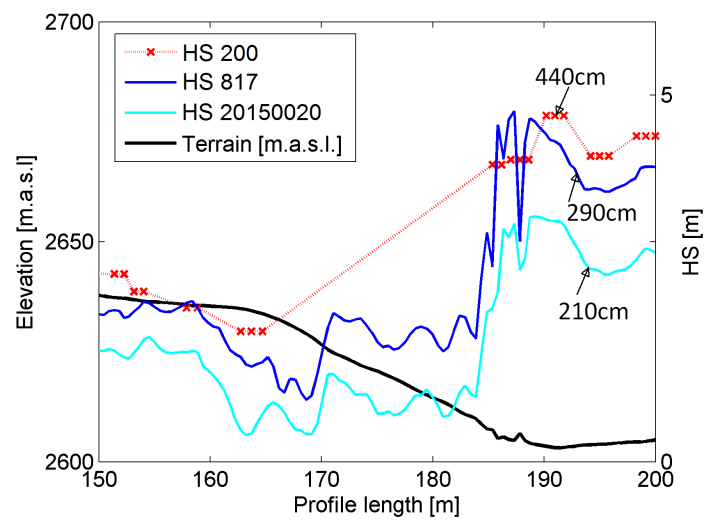

Figure 14. Snow depth profile 1 along the crown fracture of avalanche no. 200 for snow distributions of avalanches no. 200, no. 817 and no. 20150020 at the area separating CB1 from CB2. The numbers indicate the corresponding snow depth measured at the weather station. It is important to note that measurements along the crown fracture of avalanche no. 200 only exist for data points; at the line in between data points, no measurements are available.

portant release area widths, e.g. up to $700 \mathrm{~m}$, as reported in Tracz and Jamieson (2010), even propagating across terrain features that generally arrest fractures. This is also consistent with recent simulations of the slab weak layer system (Gaume et al., 2014), which show that slab thickness influences fracture propagation propensity, due to its smoothing effect on weak layer heterogeneity such as topographical irregularities.

However, the relation between surface roughness and release area size has so far only been established for very high DTM resolutions of less than $1 \mathrm{~m}$ and may not be present at coarser resolutions. This suggests that the fine-scale roughness, such as single rocks and boulders, is important for avalanche formation. It could also be one reason - beside neglecting the winter terrain - why previous studies (e.g. Vontobel (2011)) found no relation between low surface rough- 

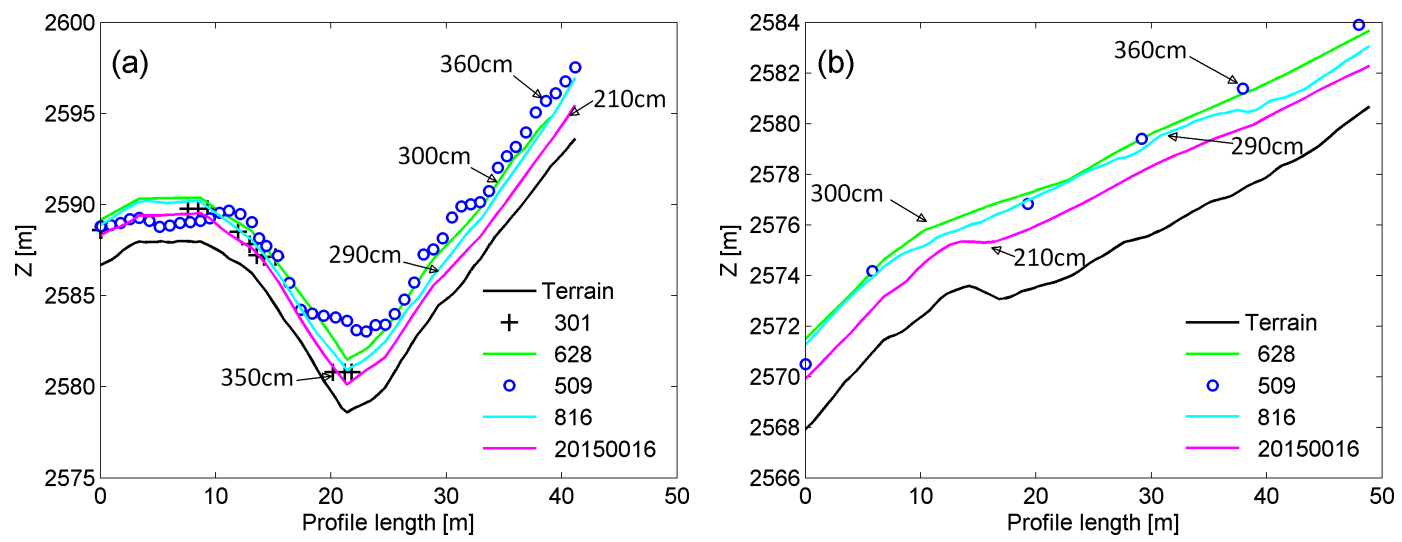

Figure 15. Elevation profiles (a) 2 and (b) 3 (Fig. 13) in snow-covered terrain before avalanche release. The numbers indicate the corresponding snow depth measured at the weather station.

ness and avalanche release areas, as they were mostly based on DTM resolutions of $2 \mathrm{~m}$ and larger.

Further, it is obvious that snowpack stability and the spatial variability of snowpack properties (Schweizer et al., 2008) affect release area size in a given situation. As an example, observed release area sizes in our dataset could have been affected by previous avalanches, significantly disturbing the layering of the snowpack, especially in very steep areas where frequent avalanches are regularly observed. Nevertheless, as we only selected avalanches that occurred under clearly unstable conditions, and considering the fact that in homogeneous terrain rather homogeneous terrain, stability patterns prevail (Harvey et al., 2012), terrain and its alteration as a result of snow accumulation can be considered, with good reason, as the main constraint for potential release area size in our dataset. This is further supported by recent mechanically based statistical modelling of the slab-weaklayer system, which emphasises the importance of changes in terrain or snow cover distribution rather than snow properties, for potential release area size (Gaume, 2012).

\section{Conclusions}

In this study, the relation between surface roughness, snow depth and release area size in a high-alpine field site was evaluated. Lidar and photogrammetry measurements before and after avalanche release were used to characterise snow distribution and surface roughness of artificially triggered avalanches. The comparison between mean surface roughness of the release area and its size showed a decrease of surface roughness with increasing release area both for the bed surface and the snow surface before avalanche release. The trend was less pronounced on the snow-free terrain, suggesting that the snow-covered winter terrain is more relevant for potential release area size than the underlying snow-free terrain.
However, the results also showed that the relation of release area size and mean surface roughness is restricted towards a minimum value of surface roughness. Reaching this value, release area size increased without significant change of mean surface roughness. This suggests that fracture propagation over large distances is facilitated once mean roughness reaches a certain minimum. At this point, a fracture will most likely self-propagate until it is arrested by major changes in the snow cover or terrain such as terrain breaks, ridges or major boulders. This is supported by surface roughness patterns in snow-covered winter terrain that appeared to be well suited to demarcate release areas. Patches of low roughness enlarged with increasing snow depth due to the levelling out of single terrain features that initially served as terrain breaks. This is in line with snow depth profiles in the release area showing that snow depth around terrain breaks, which are critical for fracture propagation, controls potential release area size. In this vein, an increase in snow depth leads to an increase in potential release area size if it is large enough to attenuate terrain features that currently delimit the release area. These findings clearly support our hypothesis of an increase of potential release area size with larger snow depth.

Snow depth - due to its link to surface roughness - could therefore serve as an important parameter to define potential release area size. Furthermore, in our study, snow depth measured at a nearby weather station was, to a considerable extent, related to observed release area size. That is because it was often representative of snow depth around critical terrain features that are able to accumulate significant quantities of snow before they become susceptible to avalanche release. This highlights the potential of a representative weather station in the process of snow cover-avalanche scenario definition. However, it has also been shown that important local snow depth differences can form for similar snow accumulation at the weather station, mainly due to avalanching and sloughing, which can both increase and decrease potential 
release area size in a given situation. This limits the explanatory power of snow depth for potential release area definition, in particular in real-time hazard assessment.

\section{Data availability}

The data used in this publication are property of the WSL Institute for Snow and Avalanche Research SLF. The data are available by submitting a specific request to Betty Sovilla (sovilla@slf.ch).

Acknowledgements. Funding for this research has been provided through the Interreg projects STRADA and STRADA 2.0 by the following partners: Amt für Wald Graubünden, Canton du Valais - Service de forêts et paysage, Regione Lombardia, ARPA Lombardia, ARPA Piemonte and Regione Autonoma Valle d'Aosta.

Edited by: M. Keiler

Reviewed by: two anonymous referees

\section{References}

Bühler, Y., Kumar, S., Veitinger, J., Christen, M., Stoffel, A., and Snehmani: Automated identification of potential snow avalanche release areas based on digital elevation models, Nat. Hazards Earth Syst. Sci., 13, 1321-1335, doi:10.5194/nhess-13-13212013, 2013.

Evans, I. S.: An integrated system of terrain analysis and slope mapping, Z. Geomorphol., Suppl. Bd. 36, 274-295, 1980.

Gauer, P.: Numerical modeling of blowing and drifting snow in Alpine terrain, J. Glaciol., 47, 97-110, 2001.

Gaume, J.: Evaluation of avalanche release depths. Combined statistical mechanical modeling, $\mathrm{PhD}$ thesis, Université de Grenoble, Grenoble, 2012.

Gaume, J., Schweizer, J., van Herwijnen, A., Chambon, G., Reuter, B., Eckert, N., and Naaim, M.: Evaluation of slope stability with respect to snowpack spatial variability, J. Geophys. Res.-Earth, 119, 1783-1799, doi:10.1002/2014JF003193, 2014.

Grohmann, C., Smith, M., and Riccomini, C.: Multiscale Analysis of Topographic Surface Roughness in the Midland Valley, Scotland, IEEE T. Geosci. Remote, 49, 1200-1213, 2011.

Gruber, S.: A mass-conserving fast algorithm to parameterize gravitational transport and deposition using digital elevation models, Water Resour. Res., 43, W06412, doi:10.1029/2006WR004868, 2007.

Gruber, U. and Margreth, S.: Winter 1999: a valuable test of the avalanche-hazard mapping procedure in Switzerland, Ann. Glaciol., 32, 328-332, doi:10.3189/172756401781819238, 2001.

Gruber, U., Dufour, F., Issler, D., Schaer, M., Dawes, N., Hiller, M., and Stoeckli, V.: Avalanche dynamics experimental site Vallée de la Sionne, Arbaz, Vallais. Final report winter 1998/1999, Report No. 732, Eidg. Institut f. Schnee- und Lawinenforschung, CH7260 Davos Dorf, 2002.

Harvey, S., Rhyner, H., and Schweizer, J.: Lawinenkunde, Bruckmann Verlag GmbH, 2012.
Maggioni, M. and Gruber, U.: The influence of topographic parameters on avalanche release dimension and frequency, Cold Reg. Sci. Technol., 37, 407-419, 2003.

McClung, D.: Characteristics of terrain, snow supply and forest cover for avalanche initiation caused by logging, Ann. Glaciol., 32, 223-229, 2001.

McClung, D. M. and Schaerer, P. A.: The Avalanche Handbook, The Mountaineers Books, Seattle, WA, 2002.

Mott, R., Schirmer, M., Bavay, M., Grünewald, T., and Lehning, M.: Understanding snow-transport processes shaping the mountain snow-cover, The Cryosphere, 4, 545-559, doi:10.5194/tc-4-5452010, 2010.

Peitzsch, E. H., Hendrikx, J., and Fagre, D. B.: Terrain parameters of glide snow avalanches and a simple spatial glide snow avalanche model, Cold Reg. Sci. Technol., 120, 237-250, doi:10.1016/j.coldregions.2015.08.002, 2015.

Sappington, J., Longshore, K., and Thomson, D.: Quantifiying Landscape Ruggedness for Animal Habitat Anaysis: A case Study Using Bighorn Sheep in the Mojave Desert, J. Wildlife Manage., 71, 1419-1426, 2007.

Schweizer, J., Bruce Jamieson, J., and Schneebeli, M.: Snow avalanche formation, Rev. Geophys., 41, 1016, doi:10.1029/2002RG000123, 2003.

Schweizer, J., Kronholm, K., Jamieson, J. B., and Birkeland, K. W.: Review of spatial variability of snowpack properties and its importance for avalanche formation, Cold Reg. Sci. Technol., 51, 253-272, 2008.

Simenhois, R. and Birkeland, K. W.: The effect of changing slab thickness on fracture propagation, Proceedings of the 2008 International Snow Science Workshop, Whistler, B.C., 755-760, 2008.

Sovilla, B., Gruber, U., Tiefenbacher, F., Felber, A., Maggioni, M., Bartelt, P., and Dufour, F.: Avalanche dynamics experimental site Vallée de la Sionne, Arbaz, Vallais. Final report winter 2002/2003, Report No. 750, Eidg. Institut f. Schnee- und Lawinenforschung, CH-7260 Davos Dorf, 2004a.

Sovilla, B., Gruber, U., Tiefenbacher, F., Hiller, M., Felber, A., Turnbull, B., Baillifard, M. A., McElwaine, J., Platzer, K., Kern, M., Bartelt, P., and Dufour, F.: Avalanche dynamics experimental site Vallée de la Sionne, Arbaz, Vallais. Final report winter 2003/2004, Report No. 753, Eidg. Institut f. Schnee- und Lawinenforschung, CH-7260 Davos Dorf, 2004b.

Sovilla, B., McElwaine, J. N., Schaer, M., and Vallet, J.: Variation of deposition depth with slope angle in snow avalanches: Measurements from Vallée de la Sionne, J. Geophys. Res., 115, F02016, doi:10.1029/2009JF001390, 2010.

Sovilla, B., Hiller, M., Koehler, A., McElwaine, J., Dufour, F., and Fischer, J.: Avalanche dynamics experimental site Vallée de la Sionne, Arbaz, Vallais, Final report winter 2014/2015, Tech. rep., WSL-Institut f. Schnee- und Lawinenforschung SLF, CH-7260 Davos Dorf, 2016.

Tracz, D. and Jamieson, J.: Characteristics of old-deep-slab avalanches., Proceedings of the 2010 International Snow Science Workshop, Squaw Valley, CA, USA, 148-154, 2010.

Vallet, J., Gruber, U., and Dufour, F.: Photogrammetric avalanche volume measurements at Vallée de la Sionne, Switzerland, Ann. Glaciol., 32, 141-146, 2001. 
van Herwijnen, A. and Heierli, J.: Measurement of crack-face friction in collapsed weak snow layers, Geophys. Res. Lett., 36, 123502, doi:10.1029/2009GL040389, 2009.

Veitinger, J., Sovilla, B., and Purves, R. S.: Influence of snow depth distribution on surface roughness in alpine terrain: a multi-scale approach, The Cryosphere, 8, 547-569, doi:10.5194/tc-8-5472014, 2014.
Veitinger, J., Purves, R. S., and Sovilla, B.: Potential slab avalanche release area identification from estimated winter terrain: a multiscale, fuzzy logic approach, Nat. Hazards Earth Syst. Sci. Discuss., 3, 6569-6614, doi:10.5194/nhessd-3-6569-2015, 2015.

Vontobel, I.: Geländeanalysen von Unfalllawinen, MS thesis, Department of Geography, University of Zurich, Zurich, 2011. 